\title{
Accelerating Neutral Hydrogen Evolution with Tungsten Modulated Amorphous Metal Hydroxides
}

\author{
Le Zhang, ${ }^{\dagger}$ Peng Fei Liu, ${ }^{\dagger}$ Yu Hang Li, ${ }^{\dagger}$ Chong Wu Wang, ${ }^{\dagger}$ Meng Yang Zu, ${ }^{\dagger}$ Huai Qin Fu, ${ }^{\dagger}$ Xiao \\ Hua Yang, ${ }^{* \dagger}$ and Hua Gui Yang ${ }^{*}$
}

† Key Laboratory for Ultrafine Materials of Ministry of Education, School of Materials Science and Engineering, East China University of Science and Technology, Shanghai, 200237 (China).

\begin{abstract}
Developing efficient, low-cost, and biocompatible electrocatalysts toward hydrogen evolution reaction (HER) in neutral environments is vital to the development of hybrid water splitting-biosynthetic system to achieve highefficiency solar-to-fuels conversion. We report here a strategy to improve the sluggish HER kinetics on $3 \mathrm{~d}$ transition metal hydroxides by incorporating tungsten through one-step electrodeposition method. The prepared amorphous $\mathrm{CoW}(\mathrm{OH})_{\mathrm{x}}$ delivers high HER activity in neutral solution, which only requires overpotentials of -73.6 and $-114.9 \mathrm{mV}$ to achieve the current densities of -10 and $-20 \mathrm{~mA} \mathrm{~cm}$ in $1.0 \mathrm{M}$ phosphate buffer solution (PBS), respectively. The activity can be ascribed to the synergistic effects between Co and W, where Co sites facilitate $\mathrm{H}_{2} \mathrm{O}$ dissociation to generate $\mathrm{H}_{\mathrm{ad}}$ intermediates, and $\mathrm{W}$ sites could effectively convert $\mathrm{H}_{\mathrm{ad}}$ to $\mathrm{H}_{2}$. Meanwhile, amorphous architecture features homogeneously dispersed Co and $\mathrm{W}$ atoms avoiding crystalline phase separation, further strengthening their collaborative interactions. Similar enhanced HER activity is also observed on electrodeposited $\mathrm{NiW}(\mathrm{OH})_{\mathrm{x}}$ electrocatalyst, suggesting the universality of this strategy for accelerating HER in neutral environments.
\end{abstract}

KEYWORDS. Transition metal hydroxides, tungsten modulation, amorphous, electrodeposition, neutral hydrogen evolution reaction.

Artificial photosynthetic technologies to achieve solarto-fuels conversion are of great promise for future energy needs. ${ }^{1}$ The hybrid water splitting-biosynthetic system can transform light, water, and carbon dioxide to the value-added chemical products with high efficiency. ${ }^{1-3}$ In this system, electrical input provided by photovoltaics drives production of hydrogen $\left(\mathrm{H}_{2}\right)$ from water splitting using biocompatible inorganic electrocatalysts. The $\mathrm{H}_{2}$ is then used by microorganisms for reducing carbon dioxide to generate biomass and fuels, such as methane and isopropyl alcohol. Considering the environmental impact as well as the biocompatibility with biocatalysts, efficient electrocatalysts are needed to speed up the sluggish HER kinetics in the $\mathrm{pH}$-neutral environments required for the biological growth. Recently, several transition metal compounds, such as oxides, ${ }^{4}$ sulfides, ${ }^{5}$ carbides,${ }^{6}$ phosphides, ${ }^{7}$ and nitrides, ${ }^{8}$ have emerged as promising HER catalysts in neutral environments, but few of them exhibit satisfactory performance for the industrial application, due to the high overpotential for large-scale production of $\mathrm{H}_{2}$. Consequently, exploration of active neutral HER electrocatalysts is an important and challenging issue for this sustainable solar-to-fuels conversion.

It is widely accepted that the mechanism of HER in neutral environments resembles that in alkaline environments, i.e., the initial water dissociation step (the Volmer step) is the rate-determining step. ${ }^{9,10}$ Thus, the kinetics of
HER in neutral environments could be accelerated by the similar method used in alkaline environments. Nenad M. Markovic et al. have reported that the $3 \mathrm{~d}$ transition metal hydroxides have the unique capacity for promoting the water dissociation in alkaline environments. ${ }^{11-16}$ Unfortunately, these hydroxides cannot convert the resulting $\mathrm{H}_{\mathrm{ad}}$ to $\mathrm{H}_{2}$ as efficiently as Pt. ${ }^{11,14,15}$ By integrating the Pt metal with the metal hydroxides $\left(\mathrm{M}(\mathrm{OH})_{2} / \mathrm{Pt}, \mathrm{M}=\mathrm{Ni}, \mathrm{Co}, \mathrm{Fe}\right){ }^{12}$ the HER kinetics on the surface of electrocatalysts can be greatly boosted. In these hybrid catalysts, the metal hydroxides promote the cleaving of $\mathrm{H}-\mathrm{OH}$ bond and production of $\mathrm{H}_{\mathrm{ad}}$ intermediates, which are then adsorbed on the nearby Pt surface to recombine into $\mathrm{H}_{2} \cdot{ }^{11-13}$ However, the high cost and scarcity of Pt limit its widespread uses. Therefore, searching for alternatives to $\mathrm{Pt}$ in $\mathrm{M}(\mathrm{OH})_{\mathrm{x}} / \mathrm{Pt}$ systems is appealing to construct novel electrocatalysts to accelerate the overall HER kinetics.

In recent years, various W-based oxides, ${ }^{17}$ carbides, ${ }^{18}$ sulfides, ${ }^{19}$ phosphides, ${ }^{20}$ and selenides ${ }^{21}$ have been reported as promising HER electrocatalysts in acidic environments, wherein $\mathrm{W}$ atoms have optimal adsorption energy for hydrogen intermediates..$^{17,18,21,22}$ Therefore, the $\mathrm{W}$ atoms might replace the above mentioned Pt to act as the absorption sites for $\mathrm{H}_{\mathrm{ad}}$. In addition, amorphous structures could ensure the homogeneous metal distribution to form an intimate contact between $3 \mathrm{~d}$ metal atoms and $\mathrm{W}$ atoms, ${ }^{23}$ further enhancing their interaction for accel- 
erating HER process. Thus, we anticipate that the neutral HER kinetics on 3d transition metal hydroxides could be accelerated by introducing $\mathrm{W}$ active sites with proper adsorption energy for $\mathrm{H}_{\mathrm{ad}}$ intermediates.

In this work, we successfully incorporate $\mathrm{W}$ into the $\mathrm{Co}(\mathrm{OH})_{2}$ via a facile one-step low-temperature electrodeposition method to fabricate amorphous $\mathrm{CoW}(\mathrm{OH})_{\mathrm{x}}$ electrocatalyst. Compared with $\mathrm{Co}(\mathrm{OH})_{\mathrm{x}}$ and $\mathrm{W}(\mathrm{OH})_{\mathrm{x}}$, the prepared $\mathrm{CoW}(\mathrm{OH})_{x}$ catalyst exhibits an extraordinary HER performance in neutral electrolyte, which only requires overpotentials of -73.6 and $-114.9 \mathrm{mV}$ to reach the current densities of -10 and $-20 \mathrm{~mA} \mathrm{~cm}^{-2}$ in $1.0 \mathrm{M}$ PBS (pH $=7$ ), respectively. We propose that the synergistic effects between $\mathrm{Co}$ and $\mathrm{W}$ not only favor the initial water dissociation step but also facilitate the following $\mathrm{H}_{\mathrm{ad}}$ recombination, simultaneously leading to the acceleration of the overall HER kinetics in neutral environment. The amorphous structure of $\mathrm{CoW}(\mathrm{OH})_{\mathrm{x}}$ enables the intimate contact of $\mathrm{Co}$ and $\mathrm{W}$ atoms, further strengthening these collaborative interactions. Furthermore, $\mathrm{NiW}(\mathrm{OH})_{\mathrm{x}}$ catalyst obtained by utilizing this synergistic strategy also exhibits much higher HER activity than that of $\mathrm{Ni}(\mathrm{OH})_{x}$ and $\mathrm{W}(\mathrm{OH})_{\mathrm{x}}$ in neutral solution.

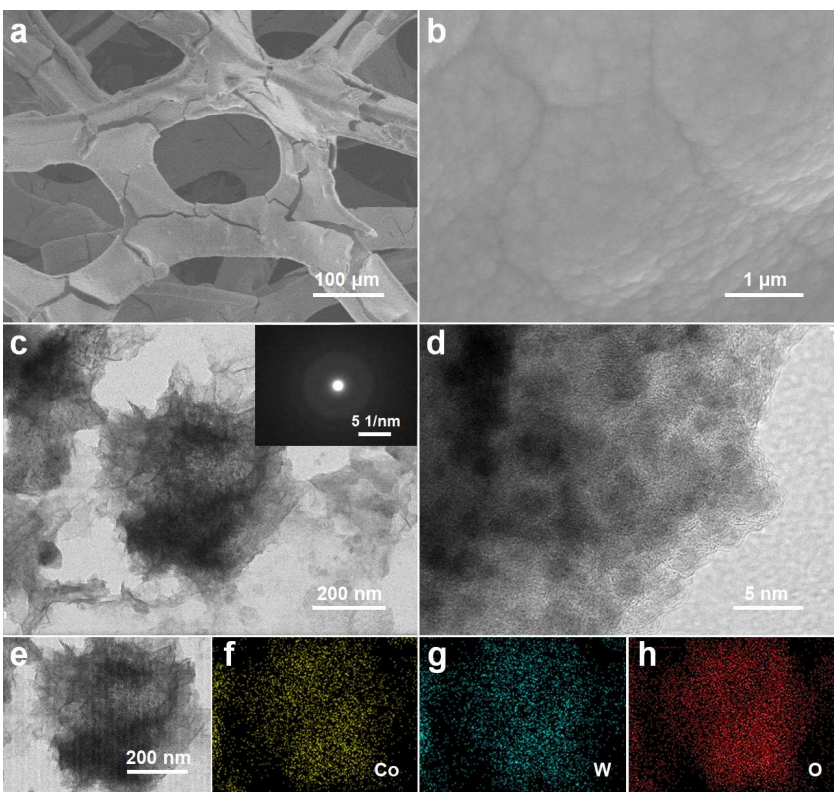

Figure 1. (a, b) SEM images and (c, d) TEM images of $\mathrm{CoW}(\mathrm{OH})_{\mathrm{x}}$. The inset in (c) is corresponding SAED pattern of $\mathrm{CoW}(\mathrm{OH})_{\mathrm{x}}$. (e-h) TEM-EDX elemental mapping images of $\mathrm{CoW}(\mathrm{OH})_{\mathrm{x}}$.

The $\mathrm{CoW}(\mathrm{OH})_{\mathrm{x}}$ electrocatalyst was prepared by galvanostatically electrodepositing Co and $\mathrm{W}$ precursors onto Ni foam substrate (see details in Experimental Section, Supporting Information). The scanning electron microscopy (SEM) images show that the $\mathrm{CoW}(\mathrm{OH})_{\mathrm{x}}$ layer is uniformly deposited onto the macroscopic $3 \mathrm{D}$ skeleton of Ni foam (Figure 1a, b), implying the high catalyst loading. This is different from the relatively flat surface observed for the blank Ni foam (Figure $\mathrm{S} 1$ ). The corresponding energy dispersive X-ray spectroscopy (EDX) mapping indicates the homogeneous distribution of $\mathrm{Co}, \mathrm{W}$, and $\mathrm{O}$ throughout the whole region (Figure $\mathrm{S}_{2}$ ). Figure 1c, d dis- play the transmission electron microscopy (TEM) images of the $\mathrm{CoW}(\mathrm{OH})_{\mathrm{x}}$ layer sonicated off from the substrate. The selected area electron diffraction (SAED) pattern shows broad and diffused rings (the inset in Figure 1c), verifying the amorphous nature of $\mathrm{CoW}(\mathrm{OH})_{\mathrm{x}}$, which can be confirmed by the missing of lattice fringes in the highresolution TEM (HRTEM) image (Figure 1d). The uniform distribution of $\mathrm{Co}, \mathrm{W}$, and $\mathrm{O}$ is demonstrated by TEMEDX elemental mapping in Figure 1e-h (see details in Figure $\mathrm{S}_{3}$ ). X-ray diffraction (XRD) pattern shown in Figure S6 exhibits no additional peaks from $\mathrm{Co}$ or $\mathrm{W}$ oxides besides the three diffraction peaks of the Ni foam substrate, further indicating the absence of long-range crystallinity in $\mathrm{CoW}(\mathrm{OH})_{\mathrm{x}}$. The inductively coupled plasma atomic emission spectroscopy (ICP-AES) analysis reveals a 3.12:1 Co:W molar ratio, which differs from the 4.53:1 Co:W surface atomic ratio obtained from X-ray photoelectron spectroscopy (XPS) (Table S1). These suggest a higher Co content on the surface than in the bulk of $\mathrm{CoW}(\mathrm{OH})_{\mathrm{x}}$.
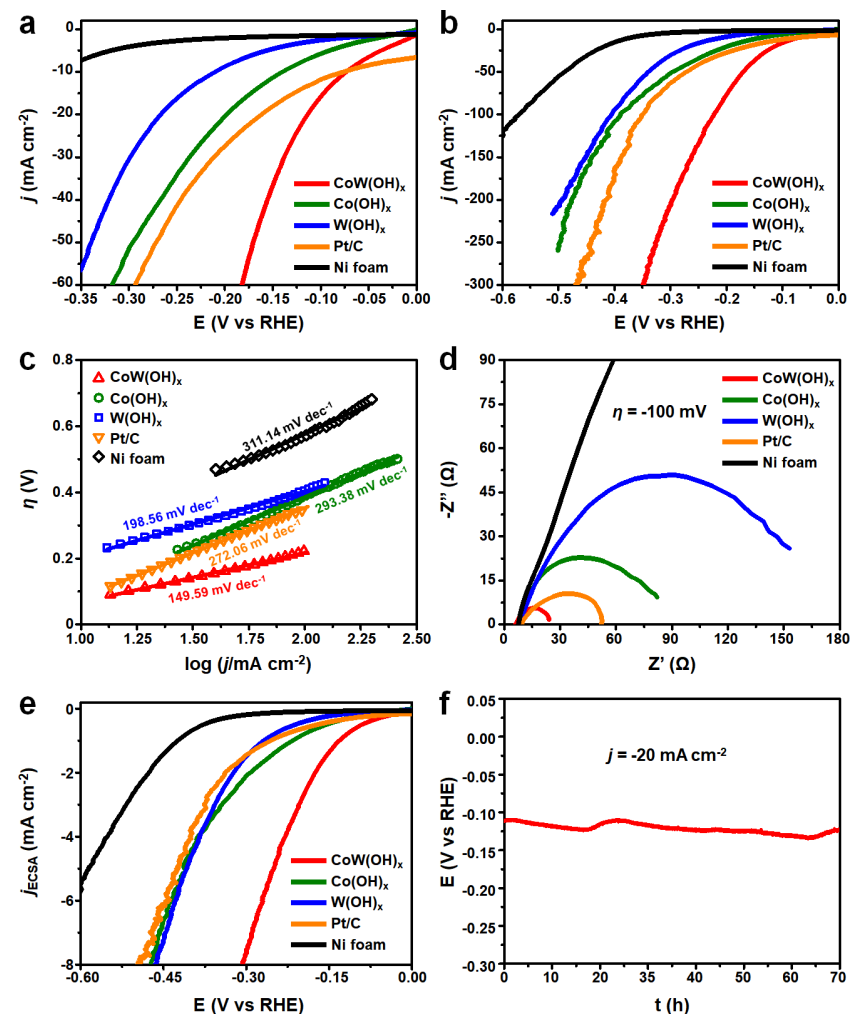

Figure 2. (a, b) Polarization curves and (c) corresponding Tafel slopes of $\mathrm{CoW}(\mathrm{OH})_{\mathrm{x}}, \mathrm{Co}(\mathrm{OH})_{\mathrm{x}}$, and $\mathrm{W}(\mathrm{OH})_{\mathrm{x}}$, along with $\mathrm{Pt} / \mathrm{C}$ and blank Ni foam for comparison. (d) Nyquist plots of all samples at $-100 \mathrm{mV}$ overpotential. (e) The specific current densities of all samples obtained by normalizing the geometric current densities to the corresponding ECSA. (f) Stability test of $\mathrm{CoW}(\mathrm{OH})_{\mathrm{x}}$ at the current density of $-20 \mathrm{~mA}$ $\mathrm{cm}^{-2}$. All measurements were performed in 1.o M PBS at room temperature.

The HER electrocatalytic activity of $\mathrm{CoW}(\mathrm{OH})_{\mathrm{x}}$ was assessed in 1.o M PBS using a standard three-electrode setup. The activity of $\mathrm{Co}(\mathrm{OH})_{\mathrm{x}}$ (Figure $\mathrm{S}_{4}, \mathrm{~S} 6$, and $\mathrm{S}_{12}$ ), $\mathrm{W}(\mathrm{OH})_{\mathrm{x}}\left(\right.$ Figure $\mathrm{S}_{5}, \mathrm{~S} 6$, and $\left.\mathrm{S}_{13}\right), \mathrm{Pt} / \mathrm{C}$, and blank Ni foam were also measured for comparison (see details in Experimental Section, Supporting Information). As shown in 
Figure $2 \mathrm{a}, \mathrm{b}$, the obtained polarization curves illustrate that $\mathrm{CoW}(\mathrm{OH})_{\mathrm{x}}$ exhibits a better performance than pure $\mathrm{Co}(\mathrm{OH})_{x}$ and $\mathrm{W}(\mathrm{OH})_{\mathrm{x}}$ in the whole potential region. The $\mathrm{CoW}(\mathrm{OH})_{\mathrm{x}}$ only requires overpotentials of -73.6 and -114.9 $\mathrm{mV}$ to reach the current densities of -10 and $-20 \mathrm{~mA} \mathrm{~cm})^{-2}$, which are much lower than that of $\mathrm{Co}(\mathrm{OH})_{\mathrm{x}}$ and $\mathrm{W}(\mathrm{OH})_{\mathrm{x}}$, as well as most recently reported nonprecious HER catalysts in neutral solution (see details in Table S3). These reveal that the presence of both $\mathrm{Co}$ and $\mathrm{W}$ is required for the significant improvement of HER activity.

The HER kinetics of all samples were then evaluated by Tafel slope. As shown in Figure $2 \mathrm{c}$, the $\mathrm{CoW}(\mathrm{OH})_{\mathrm{x}}$ has a lower Tafel slope $\left(149.59 \mathrm{mV} \mathrm{dec}^{-1}\right)$ than $\mathrm{Co}(\mathrm{OH})_{\mathrm{x}}(293.38$ $\left.\mathrm{mV} \operatorname{dec}^{-1}\right)$ and $\mathrm{W}(\mathrm{OH})_{\mathrm{x}}\left(201.25 \mathrm{mV} \operatorname{dec}^{-1}\right)$, verifying the enhanced HER kinetics. It has been reported that if the water dissociation step is the rate-determining step, the theoretical Tafel slope is around $118 \mathrm{mV} \mathrm{dec}^{-1} .9,10$ The Tafel slope of $\mathrm{CoW}(\mathrm{OH})_{\mathrm{x}}$ is close to this theoretical prediction, implying the critical role of the water dissociation step for HER in $\mathrm{CoW}(\mathrm{OH})_{\mathrm{x}}$ system. The part beyond the $118 \mathrm{mV}$ $\operatorname{dec}^{-1}$ probably derives from the low mass transport process in PBS. This point will be examined more thoroughly further below. The electrochemical impedance spectroscopy (EIS) measurements were conducted at $-100 \mathrm{mV}$ overpotential to further explore the HER kinetics. The width of the semicircle on the Z'-axis in the plots corresponds to the charge-transfer resistance $\left(R_{\mathrm{ct}}\right){ }^{24}$ Figure $2 \mathrm{~d}$ shows that $\mathrm{CoW}(\mathrm{OH})_{\mathrm{x}}$ has the lowest $R_{\mathrm{ct}}$ among all samples, suggesting the fastest HER kinetics on $\mathrm{CoW}(\mathrm{OH})_{\mathrm{x}}$ electrocatalyst.

To clarify the influence of the electrochemically active surface area (ECSA) toward the HER activity, the specific current densities were calculated by normalizing the geometric current densities to the corresponding ECSA. The ECSA was estimated through electrochemical doublelayer capacitance $\left(C_{\mathrm{dl}}\right)$ (see details in Experimental Section, Supporting Information), which is proportional to the ECSA (Figure $\left.\mathrm{S}_{7}\right)^{25-27}$ Figure $2 \mathrm{e}$ shows that the $\mathrm{CoW}(\mathrm{OH})_{\mathrm{x}}$ displays much higher specific current densities than those of $\mathrm{Co}(\mathrm{OH})_{\mathrm{x}}$ and $\mathrm{W}(\mathrm{OH})_{\mathrm{x}}$ in the whole potential region. These results demonstrate that the $\mathrm{CoW}(\mathrm{OH})_{\mathrm{x}}$ catalyst is intrinsically more active than
$\mathrm{Co}(\mathrm{OH})_{\mathrm{x}}$ and $\mathrm{W}(\mathrm{OH})_{\mathrm{x}}$.

Stability is another important criterion for electrocatalysts, which determines their practicability. Figure $2 \mathrm{f}$ shows the galvanostatic curve of $\mathrm{CoW}(\mathrm{OH})_{\mathrm{x}}$ at a constant current density of $-20 \mathrm{~mA} \mathrm{~cm}^{-2}$ in 1.0 M PBS. The overpotential fluctuates between -109 and $-133 \mathrm{mV}$ through the $7 \mathrm{o} \mathrm{h}$ continuous operation, suggesting the excellent stability. Moreover, XRD and SEM analyses for $\operatorname{CoW}(\mathrm{OH})_{x}$ after $24 \mathrm{~h}$ galvanostatic measurements indicate that the amorphous structure and morphology are well maintained (Figure S8 and S9). Additionally, no obvious degradation can be observed in the activity of $\mathrm{CoW}(\mathrm{OH})_{\mathrm{x}}$ after 10000 cyclic voltammetry cycles (Figure Sioa). The $\mathrm{CoW}(\mathrm{OH})_{\mathrm{x}}$ catalyst also exhibits a good stability at a higher current density of $-500 \mathrm{~mA} \mathrm{~cm}^{-2}$ (Figure Siob).

XPS was then performed to identify the surface element chemical states of $\mathrm{CoW}(\mathrm{OH})_{\mathrm{x}}$ in HER process. The samples for XPS analyses were obtained by testing the $\mathrm{CoW}(\mathrm{OH})_{\mathrm{x}}$ catalyst in 1.o M PBS at a constant current density of $-20 \mathrm{~mA} \mathrm{~cm}^{-2}$ for $1 \mathrm{~h}, 2 \mathrm{~h}$, as well as $4 \mathrm{~h}$, respectively. In the high-resolution Co $2 p$ spectra (Figure 3a), the Co $2 \mathrm{P}_{3 / 2}$ peak and Co $2 \mathrm{p}_{1 / 2}$ peak at 780.56 and 796.49 $\mathrm{eV}$, with two satellite peaks at 784.12 and $802.62 \mathrm{eV}$, can be attributed to the $\mathrm{Co}^{2+}$ chemical state. ${ }^{28,29}$ The separation of $15.93 \mathrm{eV}$ between $\mathrm{Co}_{2} 2 \mathrm{p}_{1 / 2}$ and Co $2 \mathrm{p}_{3 / 2}$ indicates that $\mathrm{Co}$ mainly exists as $\mathrm{Co}(\mathrm{OH})_{2}$ state. ${ }^{29}$ The peaks at 777.72 and $792.60 \mathrm{eV}$ in initial $\mathrm{CoW}(\mathrm{OH})_{\times}$spectrum are the characteristic peaks of $\mathrm{Co}^{\circ}$ state, ${ }^{28,30}$ implying the existence of metallic $\mathrm{Co}$. However, the $\mathrm{Co}^{\circ}$ peaks disappear after galvanostatic measurements, suggesting that the chemical states of $\mathrm{Co}$ on the surface of $\mathrm{CoW}(\mathrm{OH})_{x}$ have changed during HER operation. The transformation could also be observed in the $\mathrm{W}$ 4f spectra (Figure $3 \mathrm{~b}$ ). The high-resolution $\mathrm{W}$ 4f signal of initial $\mathrm{CoW}(\mathrm{OH})_{\mathrm{x}}$ can be deconvoluted into four major peaks as $\mathrm{W}^{\mathrm{o}} 4 \mathrm{f}_{7 / 2}, \mathrm{~W}^{\mathrm{o}} 4 \mathrm{f}_{5 / 2}$, $\mathrm{W}^{6+}{ }_{4} \mathrm{f}_{7 / 2}$, and $\mathrm{W}^{6+}{ }_{4 \mathrm{f}_{5 / 2}}$ at $30.80,32.92,35.05$, and $37.17 \mathrm{eV}$, respectively. ${ }^{28}$ The $W^{\mathrm{o}}$ peaks gradually decrease after $1 \mathrm{~h}$ and $2 \mathrm{~h}$ tests and only $\mathrm{W}^{6+}$ peaks remain after $4 \mathrm{~h}$ test. The high-resolution $\mathrm{O}$ is spectra are shown in Figure 3c, where the peak at $531.1 \mathrm{eV}$ is assigned to the oxygen atoms in metal hydroxides and the peak at $532.41 \mathrm{eV}$ is associated with surface-adsorbed $\mathrm{H}_{2} \mathrm{O}$ molecules. ${ }^{29}$ A new small
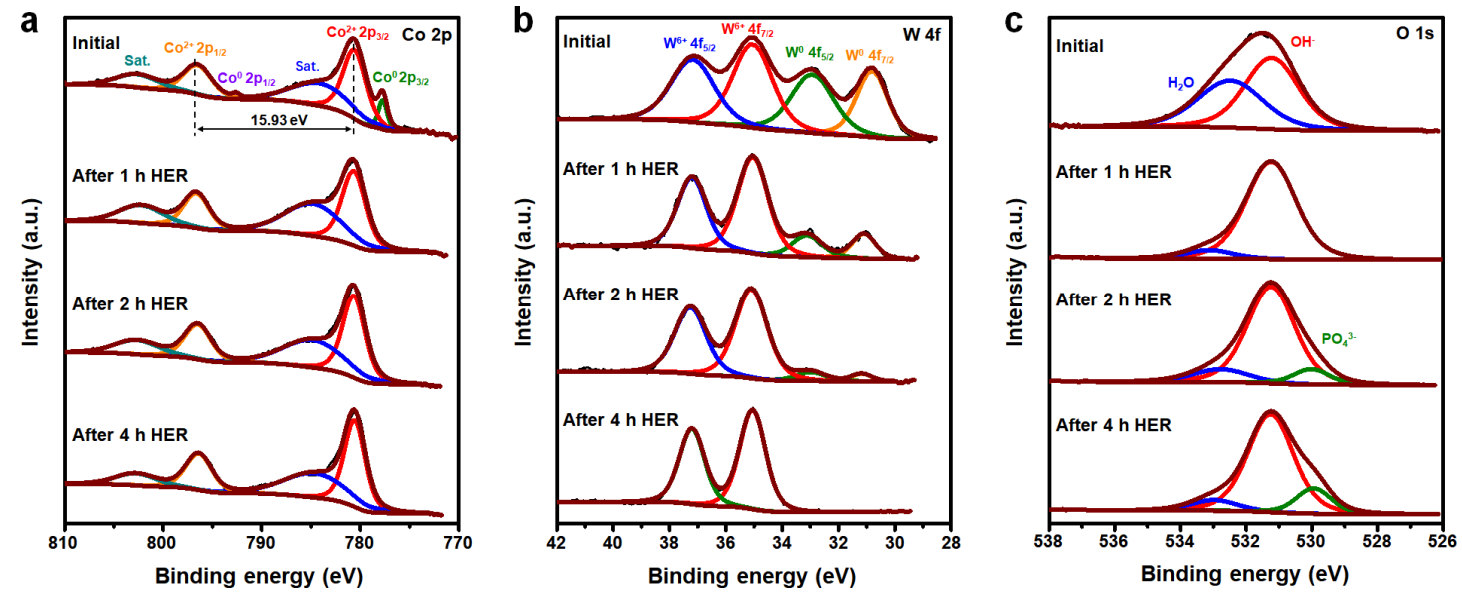

Figure 3. (a) Co 2p, (b) W 4f, and (c) O is XPS spectra of $\mathrm{CoW}(\mathrm{OH})_{\mathrm{x}}$ before and after $1 \mathrm{~h}, 2 \mathrm{~h}$, as well as $4 \mathrm{~h}$ galvanostatic measurements at the current density of $-20 \mathrm{~mA} \mathrm{~cm}^{-2}$ in $1.0 \mathrm{M} \mathrm{PBS}$, respectively. 
peak appears at $529.98 \mathrm{eV}$ in the $\mathrm{O}$ is spectrum after $2 \mathrm{~h}$ and $4 \mathrm{~h}$ measurements. This peak can be assigned to the oxygen atoms in $\mathrm{PO}_{4}{ }^{3-}$ ions. ${ }^{31}$ This is further supported by the $\mathrm{P}$ 2p spectra (Figure $\mathrm{S} 11$ ), where the peaks at $132.89 \mathrm{eV}$ correspond to $\mathrm{PO}_{4}{ }^{3-32}$ As deduced from the relative intensities of these three peaks in the $\mathrm{O}$ is spectrum after $2 \mathrm{~h}$ and $4 \mathrm{~h} \mathrm{HER,} \mathrm{the} \mathrm{majority} \mathrm{of} \mathrm{O}$ atoms are presented as hydroxides. Therefore, the main component of $\mathrm{CoW}(\mathrm{OH})_{\mathrm{x}}$ after HER is metal hydroxides.

In addition, XPS was conducted to probe the variations of the composition on the surface of $\mathrm{CoW}(\mathrm{OH})_{\mathrm{x}}$ before and after $1 \mathrm{~h}, 2 \mathrm{~h}$, as well as $4 \mathrm{~h}$ galvanostatic measurements at $-20 \mathrm{~mA} \mathrm{~cm}{ }^{-2}$ in 1.0 M PBS. The electrolytes after these measurements were also collected for ICP-AES to confirm whether the metals would leach out into the electrolyte. The atomic percentages of elements in each sample before and after these measurements obtained from XPS are shown in Table S1. The initial Co:W atomic ratio in $\mathrm{CoW}(\mathrm{OH})_{\mathrm{x}}$ is 4.53:1. However, the $\mathrm{Co}: \mathrm{W}$ ratio becomes 14.85:1 after $1 \mathrm{~h}$ HER and the ratio maintains relative stable from $1 \mathrm{~h}$ to $4 \mathrm{~h}$ measurements. The ICP-AES also detected the existence of $\mathrm{Co}^{2+}$ and $\mathrm{W}^{6+}$ in the electrolyte after $1 \mathrm{~h}$ measurement, and the concentration of each metal has negligible increase in the followed tests (Table S2). These imply that the leaching happened in the beginning and then the metals remained in a steady state in the subsequent HER process. It is noteworthy that, compared with the initial $\mathrm{Co}: \mathrm{W}$ atomic ratio, the larger $\mathrm{Co}: \mathrm{W}$ ratio after galvanostatic measurements indicates that $\mathrm{W}$ preferentially leaches out into the electrolyte, which can be further substantiated by the higher $\mathrm{W}^{6+}$ content in the electrolyte. According to these findings, it could be concluded that the final stable CoW hydroxides remained as the active materials.

Cobalt phosphate has been reported as a highperformance HER catalyst. ${ }^{33}$ Since XPS detected the existence of $\mathrm{PO}_{4}^{3-}$ on $\mathrm{CoW}(\mathrm{OH})_{\mathrm{x}}$ after galvanostatic measurements (Figure S11 and Table S1), the cobalt phosphate complexes are possibly formed during HER process to act in a comparable way. To understand the influence of $P$, the activity trends and surface element chemical states of $\mathrm{CoW}(\mathrm{OH})_{\mathrm{x}}, \mathrm{Co}(\mathrm{OH})_{\mathrm{x}}$, as well as $\mathrm{W}(\mathrm{OH})_{\mathrm{x}}$ before and after $2 \mathrm{~h}$ galvanostatic measurements at $-20 \mathrm{~mA} \mathrm{~cm}^{-2}$ in $1.0 \mathrm{M}$ PBS have been systematically studied. Although XPS detected the existence of $\mathrm{PO}_{4}^{3^{-}}$on all samples after HER tests (Figure S11-S13), the activity of each catalyst has imperceptible improvement after HER (Figure S14). $\mathrm{CoW}(\mathrm{OH})_{\mathrm{x}}$ still exhibits the best performance among all samples even after $2 \mathrm{~h} \mathrm{HER}$. $\mathrm{PO}_{4}{ }^{3-}$ may be just physically adsorbed on the surface of catalysts. These results further demonstrate that the activity of $\mathrm{CoW}(\mathrm{OH})_{\mathrm{x}}$ could be mainly attributed to the combination of $\mathrm{Co}$ and $\mathrm{W}$.

Noting that the $\mathrm{CoW}(\mathrm{OH})_{\mathrm{x}}$ was deposited onto $\mathrm{Ni}$ foam substrate, it is possible that $\mathrm{Ni}$ may be involved during HER process. In order to exclude the influence of Ni for the enhanced activity in $\mathrm{CoW}(\mathrm{OH})_{\mathrm{x}}$ system, the $\mathrm{Ni}$ foam has been changed into carbon paper $(\mathrm{CP})$ to prepare $\mathrm{CoW}(\mathrm{OH})_{x} / \mathrm{CP}, \mathrm{Co}(\mathrm{OH})_{x} / \mathrm{CP}$, and $\mathrm{W}(\mathrm{OH})_{x} / \mathrm{CP}$ samples. The SEM and corresponding elemental mapping confirm successful electrodepositions for these samples (Figure $\left.\mathrm{S}_{15}-\mathrm{S}_{17}\right)$. The polarization curves show the same trends as deposited on Ni foam: $\mathrm{CoW}(\mathrm{OH})_{\mathrm{x}} / \mathrm{CP}$ remains superior to control samples (Figure $\mathrm{S} 18$ ). These results indicate that the activity mainly derives from the deposited $\mathrm{CoW}(\mathrm{OH})_{\mathrm{x}}$ layer.
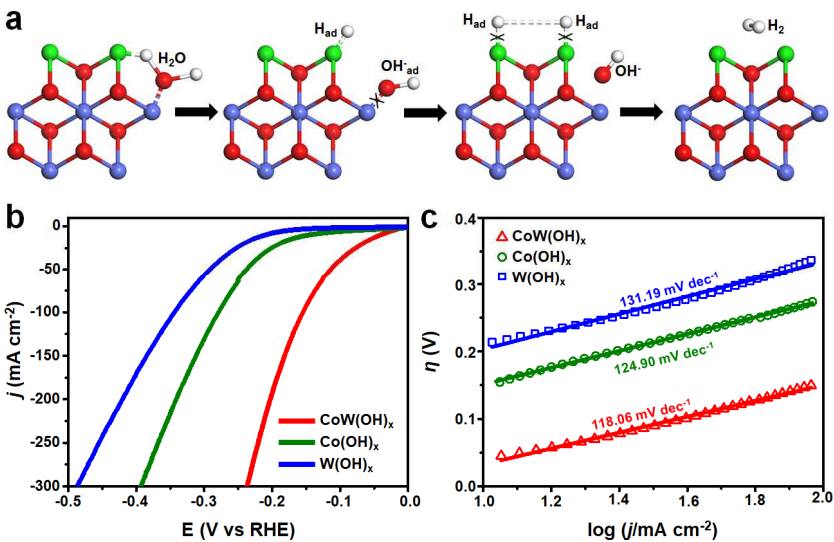

Figure 4. (a) Schematic illustration of water dissociation, $\mathrm{OH}_{\mathrm{ad}}^{-}$desorption from Co site, and $\mathrm{H}_{\mathrm{ad}}$ recombination to form $\mathrm{H}_{2}$ from $\mathrm{W}$ site. Blue, green, red, and white spheres represent $\mathrm{Co}, \mathrm{W}, \mathrm{O}$, and $\mathrm{H}$ atoms, respectively. (b) Polarization curves and (c) corresponding Tafel slopes of $\mathrm{CoW}(\mathrm{OH})_{\mathrm{x}}$, $\mathrm{Co}(\mathrm{OH})_{\mathrm{x}}$, and $\mathrm{W}(\mathrm{OH})_{\mathrm{x}}$ in $1.0 \mathrm{M} \mathrm{KOH}$.

Based on all above results and discussions, we attribute the enhanced HER performance of $\mathrm{CoW}(\mathrm{OH})_{\mathrm{x}}$ to the synergy between $\mathrm{Co}$ and $\mathrm{W}$ and propose the catalytic mechanisms described below. As schematically illustrated in Figure $4 \mathrm{a}$, when an $\mathrm{H}_{2} \mathrm{O}$ molecule is absorbed on the surface of $\mathrm{CoW}(\mathrm{OH})_{\mathrm{x}}$ catalyst, the $\mathrm{H}-\mathrm{OH}$ bond will be weakened by the interaction of $\mathrm{OH}$ group with $\mathrm{Co}$ atom and $\mathrm{H}$ atom with $\mathrm{W}$ atom, next the $\mathrm{H}_{2} \mathrm{O}$ molecule dissociates into $\mathrm{H}_{\mathrm{ad}}$ and $\mathrm{OH}_{\mathrm{ad}}^{-}$with the aid of a free electron. Finally, $\mathrm{OH}_{\text {ad }}^{-}$desorbs from the Co site, and two $\mathrm{H}_{\mathrm{ad}}$ atoms recombine into $\mathrm{H}_{2}$ and then $\mathrm{H}_{2}$ desorbs from the $\mathrm{W}$ sites. These synergistic effects in $\mathrm{CoW}(\mathrm{OH})_{\mathrm{x}}$ are similar to that in $\mathrm{M}(\mathrm{OH})_{2} / \mathrm{Pt}$ systems. ${ }^{11-13}$ In addition, the amorphous structure ensures the homogeneous distribution of $\mathrm{Co}$ and $\mathrm{W}$, which enables the intimate contact between $\mathrm{Co}$ and $\mathrm{W}$, further strengthening their cooperation. To understand this effect in depth, the HER activities of these catalysts were tested in alkaline electrolyte. Indeed, the polarization curves collected in 1.0 $\mathrm{M} \mathrm{KOH}$ clearly illustrate that $\mathrm{CoW}(\mathrm{OH})_{\mathrm{x}}$ has a better performance than $\mathrm{Co}(\mathrm{OH})_{\mathrm{x}}$ and $\mathrm{W}(\mathrm{OH})_{\mathrm{x}}$ (Figure $\left.4 \mathrm{~b}\right)$. This again demonstrates that the activity of $\mathrm{CoW}(\mathrm{OH})_{\mathrm{x}}$ could be ascribed to the collaborative interactions between $\mathrm{Co}$ and $\mathrm{W}$. The corresponding Tafel slope of $\mathrm{CoW}(\mathrm{OH})_{\mathrm{x}}$ in $1.0 \mathrm{M} \mathrm{KOH}$ (118.06 $\mathrm{mV} \mathrm{dec}^{-1}$, Figure 4c) is also close to the above mentioned theoretical value of $118 \mathrm{mV} \mathrm{dec}^{-1}$, indicating that the water dissociation step is the rate-determining step in alkaline solution. It is noteworthy that the HER performance of $\mathrm{CoW}(\mathrm{OH})_{\mathrm{x}}$ is lower in 1.0 M PBS than that in 1.0 $\mathrm{M} \mathrm{KOH} \mathrm{(Figure} \mathrm{S19a).} \mathrm{According} \mathrm{to} \mathrm{the} \mathrm{previous} \mathrm{study,}$ this is mainly resulted from the lower mass transport in neutral buffered solution, ${ }^{34}$ which is confirmed by EIS measurement at a high overpotential of $-200 \mathrm{mV}$ (Figure 
Sigb). Unfortunately, $\mathrm{CoW}(\mathrm{OH})_{\mathrm{x}}$ cannot resist the corrosion in acidic media (Figure S2o).

In order to explore the enhancing effect of $\mathrm{W}$ atoms toward other metal hydroxides, the $\mathrm{NiW}(\mathrm{OH})_{\mathrm{x}}$ was prepared by the similar electrodeposition method. The SEM and corresponding elemental mapping confirm the successful preparation of $\mathrm{NiW}(\mathrm{OH})_{\mathrm{x}}$ (Figure S22). The XPS also confirms the existence of metal hydroxide states in $\mathrm{NiW}(\mathrm{OH})_{x}$ system (Figure S24). As shown in Figure S25, compared with $\mathrm{Ni}(\mathrm{OH})_{x}$ and $\mathrm{W}(\mathrm{OH})_{x}$, the obtained $\mathrm{NiW}(\mathrm{OH})_{x}$ catalyst exhibits markedly improved HER activity in neutral solution, which only requires overpotentials of -76.2 and $-132.0 \mathrm{mV}$ to reach the current densities of -10 and $-20 \mathrm{~mA} \mathrm{~cm}^{-2}$ in 1.0 M PBS, respectively. These results demonstrate the universality of this strategy for accelerating HER in neutral environments.

In summary, we report here that the introduction of $\mathrm{W}$ into $3 \mathrm{~d}$ metal hydroxides could significantly enhance their activity for HER in neutral environments. Compared with $\mathrm{Co}(\mathrm{OH})_{\mathrm{x}}$ and $\mathrm{W}(\mathrm{OH})_{\mathrm{x}}$, the amorphous $\mathrm{CoW}(\mathrm{OH})_{\mathrm{x}}$ catalyst delivers higher HER activity in neutral solution, which only requires overpotentials of -73.6 and $-114.9 \mathrm{mV}$ to reach the current densities of -10 and $-20 \mathrm{~mA} \mathrm{~cm}^{-2}$ in 1.o M PBS, respectively. The enhancement of activity might be attributed to the synergy between $\mathrm{Co}$ and $\mathrm{W}$ as well as the amorphous structure. The Co sites promote the dissociation of $\mathrm{H}_{2} \mathrm{O}$ and production of $\mathrm{H}_{\mathrm{ad}}$, which are then adsorbed on $\mathrm{W}$ sites and recombined into $\mathrm{H}_{2}$, synergistically leading to the acceleration of the overall HER process. The amorphous structure ensures the intimate contact between Co and W, further strengthening this synergistic effect. Similar enhanced HER activity could also be observed on $\mathrm{NiW}(\mathrm{OH})_{\mathrm{x}}$ catalyst. This study may provide a new strategy to design efficient electrocatalysts for HER in neutral environments for the development of hybrid water splitting-biosynthetic system.

\section{ASSOCIATED CONTENT}

\section{Supporting Information.}

This material is available free of charge via the Internet at http://pubs.acs.org.

Detailed experimental procedures; supported physical characterizations by SEM, TEM, EDX, XRD, ICP-AES, and XPS; additional electrochemical data; table for comparison of neutral HER activity.

\section{AUTHOR INFORMATION}

\section{Corresponding Author}

* hgyang@ecust.edu.cn

*yangxh@ecust.edu.cn

\section{ACKNOWLEDGMENT}

This work was financially supported by National Natural Science Foundation of China (21573068), National Natural Science Funds for Distinguished Young Scholar (51725201), SRF for ROCS, SEM, Fundamental Research Funds for the Central Universities (222201718002, 222201714001, WD1514003), China Postdoctoral Science Foundation Funded Project (2016M601523), National Postdoctoral Program for
Innovative Talents (BX201600050), Program of Shanghai Subject Chief Scientist (15XD150130o), Shanghai Sailing Pro-

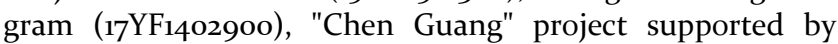
Shanghai Municipal Education Commission and Shanghai Education Development Foundation (16CG31).

\section{REFERENCES}

(1) Liu, C.; Colón, B. C.; Ziesack, M.; Silver, P. A.; Nocera, D. G. Water Splitting-Biosynthetic System with $\mathrm{CO}_{2}$ Reduction Efficiencies Exceeding Photosynthesis. Science 2016, 352, 1210-1213.

(2) Torella, J. P.; Gagliardi, C. J.; Chen, J. S.; Bediako, D. K.; Colón, B.; Way, J. C.; Silver, P. A.; Nocera, D. G. Efficient Solar-toFuels Production from a Hybrid Microbial-Water-Splitting Catalyst System. Proc. Natl. Acad. Sci. U.S.A. 2015, 112, 2337-2342.

(3) Nichols, E. M.; Gallagher, J. J.; Liu, C.; Su, Y.; Resasco, J.; Yu, Y.; Sun, Y; Yang, P.; Chang, M. C. Y.; Chang, C. J. Hybrid Bioinorganic Approach to Solar-to-Chemical Conversion. Proc. Natl. Acad. Sci. U. S. A. 2015, 112, 11461-11466.

(4) Jin, H.; Wang, J.; Su, D.; Wei, Z.; Pang, Z.; Wang, Y. In situ Cobalt-Cobalt Oxide/N-Doped Carbon Hybrids as Superior Bifunctional Electrocatalysts for Hydrogen and Oxygen Evolution. J. Am. Chem. Soc. 2015, 137, 2688-2694.

(5) Feng, L.-L.; Yu, G.; Wu, Y.; Li, G.-D.; Li, H.; Sun, Y.; Asefa, T.; Chen, W.; Zou, X. High-Index Faceted $\mathrm{Ni}_{3} \mathrm{~S}_{2}$ Nanosheet Arrays as Highly Active and Ultrastable Electrocatalysts for Water Splitting. J. Am. Chem. Soc. 2015, 137, 14023-14026.

(6) Liu, Y.; Yu, G.; Li, G.-D.; Sun, Y.; Asefa, T.; Chen, W.; Zou, $\mathrm{X}$. Coupling $\mathrm{Mo}_{2} \mathrm{C}$ with Nitrogen-Rich Nanocarbon Leads to Efficient Hydrogen-Evolution Electrocatalytic Sites. Angew. Chem. Int. Ed. 2015, 54, 10752-10757.

(7) Callejas, J. F.; McEnaney, J. M.; Read, C. G.; Crompton, J. C.; Biacchi, A. J.; Popczun, E. J.; Gordon, T. R.; Lewis, N. S.; Schaak, R. E. Electrocatalytic and Photocatalytic Hydrogen Production from Acidic and Neutral-pH Aqueous Solutions Using Iron Phosphide Nanoparticles. ACS Nano 2014, 8, 11101-11107.

(8) Yin, J.; Fan, Q.; Li, Y.; Cheng, F.; Zhou, P.; Xi, P.; Sun, S. $\mathrm{Ni}-\mathrm{C}-\mathrm{N}$ Nanosheets as Catalyst for Hydrogen Evolution Reaction. J. Am. Chem. Soc. 2016, 138, 14546-14549.

(9) Zou, X.; Zhang, Y. Noble Metal-Free Hydrogen Evolution Catalysts for Water Splitting. Chem. Soc. Rev. 2015, 44, 5148-518o.

(10) You, B.; Liu, X.; Hu, G.; Gul, S.; Yano, J.; Jiang, D.; Sun, Y. Universal Surface Engineering of Transition Metals for Superior Electrocatalytic Hydrogen Evolution in Neutral Water. J. Am. Chem. Soc. 2017, 139, 12283-12290.

(11) Subbaraman, R.; Tripkovic, D.; Strmcnik, D.; Chang, K.-C.; Uchimura, M.; Paulikas, A. P.; Stamenkovic, V.; Markovic, N. M. Enhancing Hydrogen Evolution Activity in Water Splitting by Tailoring $\mathrm{Li}^{+}-\mathrm{Ni}(\mathrm{OH})_{2}$-Pt Interfaces. Science 2011, 334, 1256-126o.

(12) Subbaraman, R.; Tripkovic, D.; Chang, K.-C.; Strmcnik, D.; Paulikas, A. P.; Hirunsit, P.; Chan, M.; Greeley, J.; Stamenkovic, V.; Markovic, N. M. Trends in Activity for the Water Electrolyser Reactions on 3d M (Ni, Co, Fe, Mn) hydr(oxy)oxide catalysts. Nat. Mater. 2012, 11, 550-557.

(13) Danilovic, N.; Subbaraman, R.; Strmcnik, D.; Chang, K.-C.; Paulikas, A. P.; Stamenkovic, V. R.; Markovic, N. M. Enhancing the Alkaline Hydrogen Evolution Reaction Activity through the Bifunctionality of $\mathrm{Ni}(\mathrm{OH})_{2} /$ Metal Catalysts. Angew. Chem. Int. Ed. 2012, 51, $12495-12498$.

(14) Yin, H.; Zhao, S.; Zhao, K.; Muqsit, A.; Tang, H.; Chang, L.; Zhao, H.; Gao, Y.; Tang, Z. Ultrathin Platinum Nanowires Grown on Single-Layered Nickel Hydroxide with High Hydrogen Evolution Activity. Nat. Commun. 2015, 6, 6430.

(15) Wang, Y.; Chen, L.; Yu, X.; Wang, Y.; Zheng, G. Superb Alkaline Hydrogen Evolution and Simultaneous Electricity Generation by Pt-Decorated $\mathrm{Ni}_{3} \mathrm{~N}$ Nanosheets. Adv. Energy Mater. 2016, 7, 1601390 . 
(16) Wang, L.; Lin, C.; Huang, D.; Chen, J.; Jiang, L.; Wang, M.; Chi, L.; Shi, L.; Jin, J. Optimizing the Volmer Step by SingleLayer Nickel Hydroxide Nanosheets in Hydrogen Evolution Reaction of Platinum. ACS Catal. 2015, 5, 3801-3806.

(17) Li, Y. H.; Liu, P. F.; Pan, L. F.; Wang, H. F.; Yang, Z. Z.; Zheng, L. R.; Hu, P.; Zhao, H. J.; Gu, L.; Yang, H. G. Local Atomic Structure Modulations Activate Metal Oxide as Electrocatalyst for Hydrogen Evolution in Acidic Water. Nat. Commun. 2015, 6, 8064 .

(18) Gong, Q.; Wang, Y.; Hu, Q.; Zhou, J.; Feng, R.; Duchesne, P. N.; Zhang, P.; Chen, F.; Han, N.; Li, Y.; Jin, C.; Li, Y.; Lee, S.-T. Ultrasmall and Phase-Pure $\mathrm{W}_{2} \mathrm{C}$ Nanoparticles for Efficient Electrocatalytic and Photoelectrochemical Hydrogen Evolution. Nat. Commun. 2016, 7, 13216.

(19) Cheng, L.; Huang, W.; Gong, Q.; Liu, C.; Liu, Z.; Li, Y.; Dai. H. Ultrathin $\mathrm{WS}_{2}$ Nanoflakes as a High-Performance Electrocatalyst for the Hydrogen Evolution Reaction. Angew. Chem. Int. Ed. 2014, 53, 7860-7863.

(20) Xing, Z.; Liu, Q.; Asiri, A. M.; Sun, X. High-Efficiency Electrochemical Hydrogen Evolution Catalyzed by Tungsten Phosphide Submicroparticles. ACS Catal. 2015, 5, 145-149.

(21) Tsai, C.; Chan, K.; Abild-Pedersen, F.; Jens K. Nørskov, J. K. Active Edge Sites in $\mathrm{MoSe}_{2}$ and WSe $\mathrm{W}_{2}$ Catalysts for the Hydrogen Evolution Reaction: a Density Functional Study. Phys. Chem. Chem. Phys. 2014, 16, 13156-13164.

(22) Voiry, D.; Yang, J.; Chhowalla, M. Recent Strategies for Improving the Catalytic Activity of $2 \mathrm{D}$ TMD Nanosheets Toward the Hydrogen Evolution Reaction. Adv. Mater. 2016, 28, 61976206.

(23) Zhang, B.; Zheng, X.; Voznyy, O.; Comin, R.; Bajdich, M.; García-Melchor, M.; Han, L.; Xu, J.; Liu, M.; Zheng, L.; García de Arquer, F. P.; Dinh, C. T.; Fan, F.; Yuan, M.; Yassitepe, E.; Chen, N.; Regier, T.; Liu, P.; Li, Y.; Luna, P. D.; Janmohamed, A.; Xin, H. L.; Yang, H.; Vojvodic, A.; Sargent. E. H. Homogeneously Dispersed Multimetal Oxygen-Evolving Catalysts. Science 2016, 352, 333-337.

(24) Zhang, J.; Wang, T.; Liu, P.; Liao, Z.; Liu, S.; Zhuang, X.; Chen, M. Zschech, E.; Feng, X. Efficient Hydrogen Production on $\mathrm{MoNi}_{4}$ Electrocatalysts with Fast Water Dissociation Kinetics. Nat. Commun. 2017, 8, 15437.

(25) McCrory, C. C. L.; Jung, S.; Ferrer, I. M.; Chatman, S. M.; Peters, J. C.; Jaramillo, T. F. Benchmarking Hydrogen Evolving Reaction and Oxygen Evolving Reaction Electrocatalysts for Solar Water Splitting Devices. J. Am. Chem. Soc. 2o15, 137, 43474357.

(26) Zhang, R.; Wang, X.; Yu, S.; Wen, T.; Zhu, X.; Yang, F.; Sun, X.; Wang, X.; Hu, W. Ternary $\mathrm{NiCO}_{2} \mathrm{P}_{\mathrm{x}}$ Nanowires as $\mathrm{pH}-$ Universal Electrocatalysts for Highly Efficient Hydrogen Evolution Reaction. Adv. Mater. 2017, 29, 1605502.

(27) Lu, X.; Zhao, C. Electrodeposition of Hierarchically Structured Three-Dimensional Nickel-Fron Electrodes for Efficient Oxygen Evolution at High Current Densities. Nat. Commun. 2015, 6, 6616.

(28) Dai, H.-B.; Liang, Y.; Wang, P. Effect of Trapped Hydrogen on the Induction Period of Cobalt-Tungsten-Boron/Nickel Foam Catalyst in Catalytic Hydrolysis Reaction of Sodium Borohydride. Catal. Today 2011, 170, 27-32.

(29) Xue, T.; Wang, X.; Lee, J.-M. Dual-Template Synthesis of $\mathrm{Co}(\mathrm{OH})_{2}$ with Mesoporous Nanowire Structure and its Application in Supercapacitor. J. Power Sources 2012, 201, 382-386.

(30) Dai, W.-L.; Qiao, M.-H.; Deng, J.-F. XPS Studies on a Novel Amorphous Ni-Co-W-B Alloy Powder. Appl. Surf. Sci. 1997, 120, 119-124.

(31) Allen, G. C.; Ciliberto, E.; Fragalà, I.; Spoto, G. Surface and Bulk Study of Calcium Phosphate Bioceramics Obtained by Metal Organic Chemical Vapor Deposition. Nucl. Instrum. Methods Phys. Res. B 1996, 116, 457-46o.
(32) Xie, L.; Zhang, R.; Cui, L.; Liu, D.; Hao, S.; Ma, Y.; Du, G.; Asiri, A. M.; Sun, X. High-Performance Electrolytic Oxygen Evolution in Neutral Media Catalyzed by a Cobalt Phosphate Nanoarray. Angew. Chem. Int. Ed. 2017, 56, 1064-1068.

(33) Cobo, S.; Heidkamp, J.; Jacques, P.-A.; Fize, J.; Fourmond, V.; Guetaz, L.; Jousselme, B.; Ivanova, V.; Dau, H.; Palacin, S.; Fontecave, M.; Artero, V. A Janus Cobalt-Based Catalytic Material for Electro-Splitting of Water. Nat. Mater. 2012, 11, 802-807.

(34) Shinagawa, T; Takanabe, K. Towards Versatile and Sustainable Hydrogen Production through Electrocatalytic Water Splitting: Electrolyte Engineering. ChemSusChem 2017, 10, 13181336. 

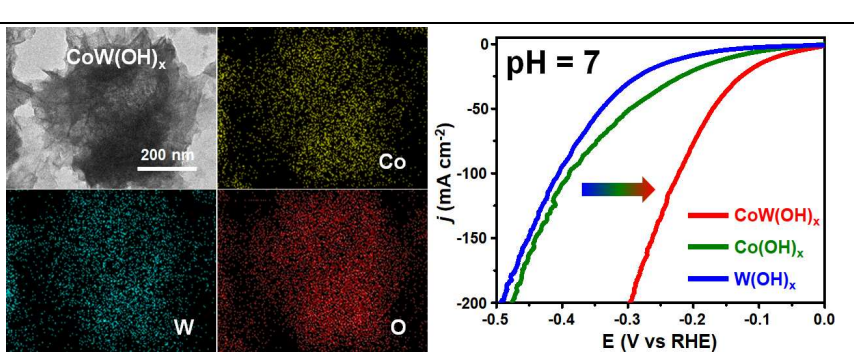

10

11

12

13

14

15

16

17

18

19

20

21

22

23

24

25

26

27

28

29

30

31

32

33

34

35

36

37

38

39

40

41

42

43

44

45

46

47

48

49

50

51

52

53

54

55

56

57

58

59

60

ACS Paragon Plus Environment 


\title{
Letter
}

Subscriber access provided by Kaohsiung Medical University

\section{Accelerating Neutral Hydrogen Evolution with Tungsten Modulated Amorphous Metal Hydroxides}

\author{
Le Zhang, Peng Fei Liu, Yu Hang Li, Chong Wu Wang, Meng \\ Yang Zu, Huai Qin Fu, Xiao Hua Yang, and Hua Gui Yang \\ ACS Catal., Just Accepted Manuscript • DOI: 10.1021/acscatal.8b01076 • Publication Date (Web): 02 May 2018 \\ Downloaded from http://pubs.acs.org on May 2, 2018
}

\section{Just Accepted}

"Just Accepted" manuscripts have been peer-reviewed and accepted for publication. They are posted online prior to technical editing, formatting for publication and author proofing. The American Chemical Society provides "Just Accepted" as a service to the research community to expedite the dissemination of scientific material as soon as possible after acceptance. "Just Accepted" manuscripts appear in full in PDF format accompanied by an HTML abstract. "Just Accepted" manuscripts have been fully peer reviewed, but should not be considered the official version of record. They are citable by the Digital Object Identifier (DOI®). "Just Accepted" is an optional service offered to authors. Therefore, the "Just Accepted" Web site may not include all articles that will be published in the journal. After a manuscript is technically edited and formatted, it will be removed from the "Just Accepted" Web site and published as an ASAP article. Note that technical editing may introduce minor changes to the manuscript text and/or graphics which could affect content, and all legal disclaimers and ethical guidelines that apply to the journal pertain. ACS cannot be held responsible for errors or consequences arising from the use of information contained in these "Just Accepted" manuscripts. 